\title{
Aproveitamento da água de chuva para lavagem de máquinas agrícolas e veículos: Estudo de caso do Colégio Politécnico da Universidade Federal de Santa Maria
}

\author{
Rainwater use for wash agricultural machinery and vehicles: \\ Case study of the Polytechnic School of Federal University of Santa Maria \\ Cicero Urbanetto Nogueira ${ }^{1}$, Helena Maria Camilo de Moraes Nogueira ${ }^{2}$, Antonio Luiz Fantinel ${ }^{3}$, Sérgio Luiz Jahn ${ }^{4}$ e \\ Richard Alberto Rodríguez Padrón ${ }^{5}$ \\ 1,2 Professor, mestre em Engenharia de Produção, Colégio Politécnico da Universidade Federal de Santa Maria, RS, Brasil \\ ${ }^{3}$ Mestrando em Engenharia de Produção, Universidade Federal de Santa Maria \\ ${ }^{4}$ Professor, Doutor em Engenharia Química, Universidade Federal de Santa Maria \\ ${ }^{5}$ Doutorando em Engenheira Agrícola, Universidade Federal de Santa Maria
}

\begin{abstract}
Resumo
Os estudos sobre manejo e aproveitamento dos recursos hídricos vêm sendo um dos focos de pesquisa que está procurando diferentes alternativas para o aproveitamento dos recursos naturais com sustentabilidade. O estudo teve como objetivo o planejamento, a execução e a estimação do retorno econômico do aproveitamento da água de chuva, para lavagem de veículos, máquinas e implementos agrícolas. O estudo foi realizado para o setor de Mecanização do Colégio Politécnico da Universidade Federal de Santa Maria, no período de março de 2011 a fevereiro de 2013. O telhado do setor de Mecanização possui uma área de captação de $215,45 \mathrm{~m}^{2}$. Foram instalados cinco reservatórios de 7.000 litros cada um. Reduziu-se o consumo de água proveniente do subsolo em 100\%. Foram utilizados 458.120,25 litros de água proveniente das chuvas e destinadas para as atividades propostas. Os reservatórios foram o maior investimento, representando $63 \%$, seguido da lavadora $27 \%$ e outros $10 \%$ do total dos custos. Obteve-se uma economia total de $R \$ 2.009,66$ e, mensalmente de $R \$ 83,74$ em função do custo da água. O sistema de aproveitado de água de chuva é uma das alternativas para a diminuição do consumo de água de outras fontes.
\end{abstract}

Palavras-chave: Água pluvial. Sustentabilidade. Viabilidade. Água do subsolo.

\begin{abstract}
The studies on management and use of water resources has been one focus of several research, they are looking for alternatives to the use of natural resources and sustainability. The study aimed to planning, execution and estimate the economic return of the use of rainwater for washing vehicles, agricultural machinery and implements. The study was conducted for the sector of mechanization of the Polytechnic School of the Federal University of Santa Maria, from March 2011 to February 2013. The roof of agricultural mechanization sector has a catchment area of $215.45 \mathrm{~m}^{2}$. Five tanks of 7000 liters each were installed. The underground water consumption was reduced by $100 \%$. It was used 458,120.25 liters of water from rainy and intended for the proposed activities. The reservoirs were the largest investment, accounting for $63 \%$, followed by washing $27 \%$ and $10 \%$ of total costs. A total savings of $R$ \$ 2009.66 was obtained and monthly $R$ \$ 83.74 depending on the costs of water. The system of rainwater harvesting is an alternative to reduce the consumption of water from other sources.
\end{abstract}

Keywords: Rainwater. Sustainability. Viability. Underground water. 


\section{Introdução}

A captação e o aproveitamento das águas pluviais caracterizam-se por ser um processo milenar, existem registros antigos do aproveitamento da água de chuva desde 850 a.C, adotado por civilizações como Astecas, Maias e Incas referindo-se as inscrições em Pedra no Oriente Médio, onde os governantes da época sugerem a construção de reservatórios de água de chuva em cada residência. A conservação da qualidade e quantidade da água do planeta, através de práticas de economia, como o uso racional e as fontes alternativas, fazem parte dos princípios da sustentabilidade e está atualmente em expansão sendo adotada em diversos países, sobretudo nas áreas urbanas brasileiras (GIACCHINI, 2010).

A superfície do planeta Terra é coberta por $70 \%$ de água, sendo que $97 \%$ são de água salgada, imprópria para consumo sem ser processada. Os $3 \%$ restantes correspondem à água doce, que se encontra, em sua maior parte, nas geleiras, ou seja, menos de 1\% está disponível e boa parte desse conteúdo encontra-se muitos metros abaixo do solo, nos lençóis freáticos. Segundo o Programa das Nações Unidas para o Desenvolvimento (PNUD, 2006), cerca de um bilhão de pessoas não têm acesso à água tratada no mundo e 2,6 bilhões não têm instalações básicas de saneamento, principalmente na África e na Ásia. Metade dos leitos hospitalares são ocupados por doenças causadas pelo uso de água imprópria para o consumo humano, provocando a morte de aproximadamente 4.900 crianças menores de cinco anos por dia, por diarreia.

Diante da polêmica existente a nível mundial, com respeito ao meio ambiente, a água vem tendo destaque no que trata da sua preservação, contaminação e de seu uso excessivo e errôneo pelas pessoas. Devido a sua escassez cada vez mais intensa é necessário um consumo mais controlado e eficiente deste bem tão importante para a vida dos seres vivos. Dessa forma, torna-se relevante, estudos que tratam do reaproveitamento de água das chuvas na utilização em práticas não potáveis em nosso dia-dia (Fantinel et al., 2013).

Os sistemas de aproveitamento da água da chuva ou pluviais são utilizados desde a história antiga, com cisternas para armazenamento de água para o consumo humano. Atualmente, as águas utilizadas para o consumo humano necessitam de tratamento adequado para garantir sua potabilidade, porém as águas utilizadas para outros fins não alimentares, como limpezas, irrigações e lavagens de veículos ou máquinas podem ser oriundas de precipitações. A água tornou-se fator limitante para o desenvolvimento urbano, industrial e agrícola nas regiões áridas e semiáridas brasileiras. Pessoas e entidades ligadas à gestão dos recursos hídricos estudam continuamente novas fontes de recursos para complementar à pequena disponibilidade de água disponível (HESPANHOL, 2002).

O recolhimento da água da chuva possibilita a utilização da mesma para diversos fins, diminuindo o uso da água do subsolo e contribuindo na preservação do meio ambiente e evitando o desperdício deste bem valioso, afirmada por Ornelas (2004, p. 14), “a substituição da água potável por água de reuso, onde essa substituição for possível, ajuda a manter a sustentabilidade desse valioso recurso". Citando o "reuso de águas recuperadas de efluentes domésticos em vasos sanitários é uma das alternativas mais interessantes para reduzir a demanda urbana de água potável" (ORNELAS, 2004, p. 141). "Fundamental para a vida dos seres vivos, sendo que o ser humano necessita dela de forma direta e indireta diariamente" (ALT, 2009, p. 4).

A água é um recurso natural essencial para a sobrevivência do ser humano e tem sofrido demanda crescente por sua utilização, principalmente no setor agrícola para fins de irrigação. No Rio Grande do Sul, o consumo da água pelas lavouras de arroz tem levantado à questão da degradação da qualidade da água dos rios, necessitando de uma mudança cultural quanto ao seu uso.

Para amenização deste problema, Cohim et al. (2007, p. 9) citam que a captação e utilização de águas pluviais para a irrigação, quando bem analisado e dimensionado, "apresenta-se como uma alternativa viável, possibilitando a redução de custos, diminuindo a pressão nos mananciais, 
permitindo o direcionamento destes recursos para atendimento a consumos mais nobres, para uma parcela maior da população".

O reuso reduz o uso de água de mananciais, devido à substituição da água potável por água não potável, atualmente esta sendo discutida, colocando em evidência e sendo utilizada em alguns países, criando o conceito de substituição de mananciais. Esta prática é possível em função da qualidade requerida da água para um uso específico (não potável). Deixando de serem utilizados grandes volumes de água potável, pelo reuso quando se utiliza água de qualidade inferior (NBR-13.969/97).

O sistema de aproveitamento da água da chuva torna-se uma medida não convencional de conservação de água potável, que vem sendo utilizada em países desenvolvidos, como Estados Unidos, Japão e Alemanha, onde este tipo de sistema representa um mecanismo eficiente. Em algumas cidades do nordeste brasileiro utilizam-se o suprimento de água, devido à escassez sofrida na maior parte do ano devido ao clima semiárido (SANTOS et al., 2008).

Para Alt (2009, p. 5), "a captação da água de chuva constitui alternativa eficaz, como forma de disponibilizar água "de boa qualidade" em diversas regiões e ainda controlar a vazão nos escoamentos superficiais das cidades".

A coleta de água de chuva ocorre em áreas impermeáveis, normalmente telhados. A primeira água que cai no telhado, lavando-o apresenta um grau de contaminação bastante elevado e, por isso, a primeira água deve ser descartada. A água de chuva coletada através de calhas, condutores verticais e horizontais é armazenada em reservatório, podendo ser de diferentes materiais. Essa água deverá ser utilizada somente para consumo não potável, como em irrigação de jardins, pomares e para lavagem de máquinas agrícolas (SANTOS et al., 2008).

De acordo com MAY (2004), a viabilidade do sistema depende basicamente de três fatores: precipitação, área de coleta e demanda. O reservatório de água da chuva, por ser o componente mais dispendioso do sistema, deve ser projetado de acordo com as necessidades do usuário e com a disponibilidade pluviométrica local para dimensioná-lo corretamente, sem inviabilizar economicamente o sistema. Necessitando apenas de um dispositivo que afaste folhas e galhos porque estes dificultam o bom funcionamento do sistema (JAQUES, 2005).

Na visão de Giacchini e Filho (2008, p. 7), "uma escola que implante o sistema de aproveitamento da água de chuva, certamente estará contribuindo para a formação de cidadãos mais conscientes da sua relação com o com o meio ambiente, pois a educação ambiental vivenciada na prática é muito mais significativa". Para os autores os alunos poderão vivenciar na íntegra o funcionamento do sistema, onde poderão utilizar esta água nas práticas da horta, para limpeza ou descargas de vasos sanitários. Assim "todos podem se beneficiar com o aproveitamento da água de chuva, pois escola lucra com a economia de água, os alunos serão incentivadores do processo na sociedade e a natureza será preservada". No estudo de caso desenvolvido na Indústria Fundição Hubner, ocorreu à viabilidade da utilização da água de chuva para práticas diárias não potáveis com uma redução de aproximadamente $50 \%$ de água potável utilizada (GIACCHINI; FILHO, 2008).

O Colégio Politécnico da Universidade Federal de Santa Maria utiliza a água que provém do subsolo e parte dela destina-se à lavagem de veículos, máquinas e equipamentos agrícolas utilizados nas lavouras. Ao mesmo tempo, ele possui várias edificações com grandes áreas de cobertura que poderiam ser utilizadas para a captação da água da chuva para a reutilização nessas práticas.

Sendo assim, o presente estudo teve como objetivo o planejamento, a execução e a estimação do retorno econômico do aproveitamento da água de chuva, para lavagem de veículos, máquinas e implementos agrícolas, visado o no consumo da agua do subsolo para essas atividades.

\section{Materiais e métodos}

O estudo foi conduzido no setor de Mecanização do Colégio Politécnico da Universidade

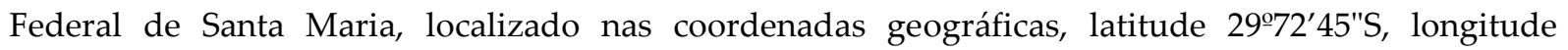
53ำ72'05"W e altitude de 103 metros, no período de março de 2011 a fevereiro de 2013. O clima na região, segundo a classificação de Köppen-Geiger é subtropical úmido (Cfa). Os monitoramentos dos dados climáticos foram obtidos na estação meteorológica automática, localizada aproximadamente a

REGET - V. 20, n. 1, jan.- abr. 2016, p.325-333 
$300 \mathrm{~m}$, vinculada ao Instituto Nacional de Meteorologia (INMET). A evaporação, a temperatura e a precipitação média anual variam de $800-1200 \mathrm{~mm}, 18-20^{\circ} \mathrm{C}$ e $1450-1650 \mathrm{~mm}$, respectivamente, segundo o (INMET).

Foi avaliado o local para serem colocados os reservatórios, com os seguintes critérios: proximidade do local de coleta (telhado); proximidade do local de consumo (rampa de lavagem); visibilidade das instalações; visando à economia e a sustentabilidade. A área de captação do telhado é de 215,45 $\mathrm{m}^{2}$. A distância para interligar a área do telhado às caixas de reservatório foi de $6 \mathrm{~m}$, utilizaram-se canos de PVC de $150 \mathrm{~mm}$. A dimensão da rampa é de $15 \mathrm{~m}$ de comprimento, $3 \mathrm{~m}$ de largura e 1,7 m de altura. Foi analisado a precipitação da localidade em um período de 5 anos, para estimar o volume de chuva possível a ser captado. Também, calculou-se o número de veículos em lavagem e o volume consumido diário, para os cálculos dos reservatórios. Foram instalados 5 reservatórios para capacidade total de 35.000 litros, cada um de 7.000 litros, colocando-se 2 em baixo da rampa e 3 em cima da rampa e interligados por canos de PVC de $50 \mathrm{~mm}$ e colocou-se um vertedouro para não extrapolar o limite da capacidade. Foi instalada uma lavadora universal (modelo luz 3501) com uma mangueira de alta pressão de $15 \mathrm{~m}$.

Foram elencados e analisados os custos das instalações e dos equipamentos necessários para a implantação do sistema de coleta e utilização da água de chuva. Com o levantamento da precipitação pluviométrica da localidade e da área do telhado, calculou-se o volume mensal captado pela metodologia descrita por (Tomaz, 2010, 2011), pela seguinte equação:

onde:

$$
\mathrm{V}=\mathrm{P} \times \mathrm{A} \times \mathrm{C} \times \eta \text { fator de captação }
$$

$\mathrm{V}=$ volume anual, mensal ou diário de água de chuva aproveitável, em litros;

$\mathrm{P}=$ precipitação média anual, mensal ou diária, em milímetros;

$\mathrm{A}=$ área de coleta, em metros quadrados;

$\mathrm{C}=$ coeficiente de runoff. Normalmente $\mathrm{C}=0,95$.

$\eta$ fator de captação = eficiência do sistema de captação, levando em conta o descarte do first flush.

A "eficiência do first flush ou do descarte de filtros variam de 0,50 a 0,90 ", podendo-se adotar: $C$ x $\eta$ fator de captação=0,80, em ocasiões quando não se têm dados.

Estimou-se a economia financeira proporcionada pela utilização de água das chuvas a partir dos valores cobrados na cidade nos anos de 2011, 2012 e 2013. No ano de 2011, a tarifa básica de água cobrada pela concessionária era de $\mathrm{R} \$ 16,23$ mais a taxa de $\mathrm{R} \$ 3,43$ para cada $\mathrm{m}^{3}$ de água consumida. De 2012 a 2013, a tarifa básica de água era de $R \$ 17,07$ mais a taxa de $R \$ 3,61$ para cada $\mathrm{m}^{3}$ de água consumida.

\section{Resultados}

As precipitações mensais registradas na localidade em estudo, segundo o Instituto Nacional de Meteorologia (INMET, 2013) se apresentam na (Figura 1). Os meses com maiores precipitações foram outubro de 2011, setembro, outubro e dezembro de 2012, com médias superiores a 227 milímetros, sendo os meses de outubro e dezembro de 2012 com as maiores precipitações. Já o mês de dezembro de 2011 apresentou menor precipitação, seguido pelos meses de junho de 2012 e novembro de 2011, precipitações estas abaixo da média de 116,66 milímetros no período analisado. A localidade apresenta um volume médio de precipitação que justifica o recolhimento para o aproveitamento da água de chuva, suprindo às necessidades hídricas do setor em estudo. 


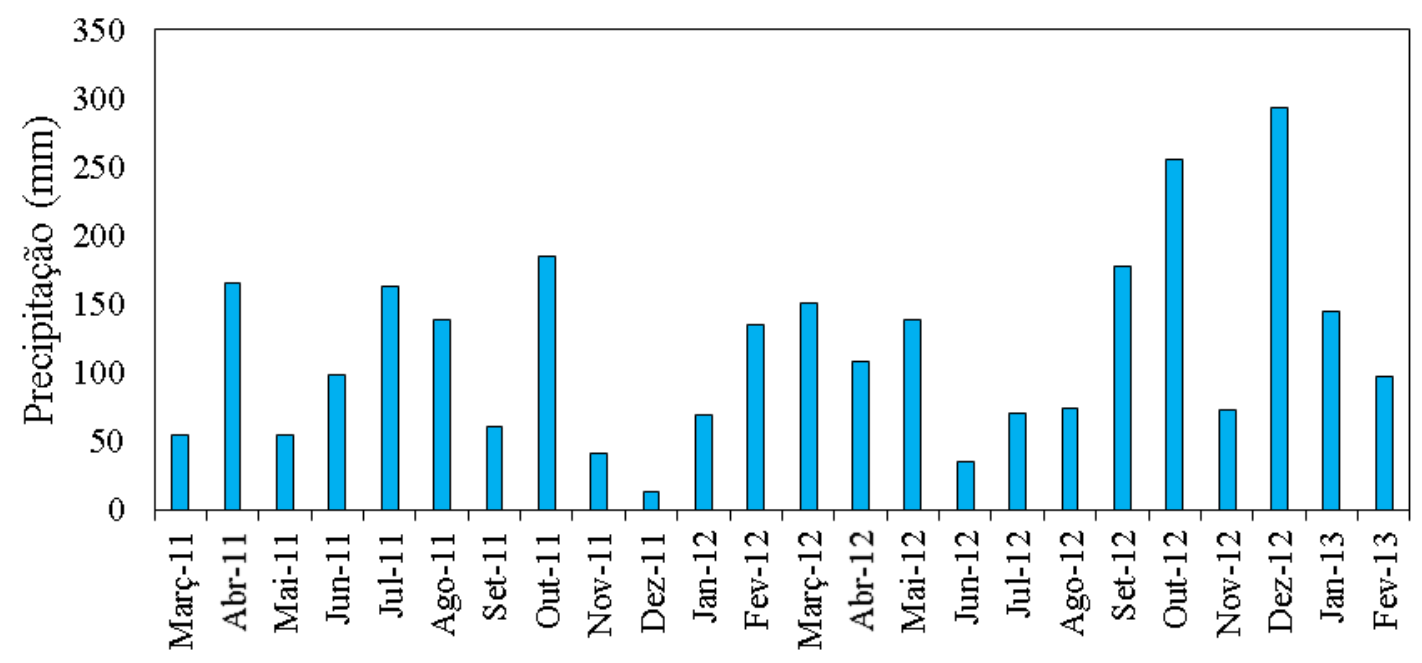

Meses

Figura 1 - Precipitações mensais na localidade em estudo (Santa Maria-RS)

O volume calculado da água de chuva, no período de estudo, apresenta-se na (Figura 2). No período de 24 meses (março-2011 a fevereiro-2013), o volume foi de 482.607,99 litros, com média mensal de 20.108,67 litros. Nos meses de primavera, a captação foi superior a 30.000 litros, tais como: outubro de 2011; setembro, outubro e dezembro de 2012 e o mês de dezembro de 2011 foi o que obteve a menor captação pela ocorrência de forte estiagem na região. No setor, para a lavagem dos veículos, máquinas e implementos agrícolas, utilizaram-se 8 horas semanais, com vazão de 900 litros hora-1, gerou o consumo de 7.200 litros de água por semana, totalizando 32.400 litros mensais. Foram utilizados 458.120,25 litros de água proveniente das chuvas e destinadas para as atividades acima propostas, tendo assim relação direta com a sustentabilidade. Nos meses que houve déficit hídrico para a realização das atividades, utilizou-se o critério da não lavagem, até acontecer a reposição dos reservatórios pela água de chuva.

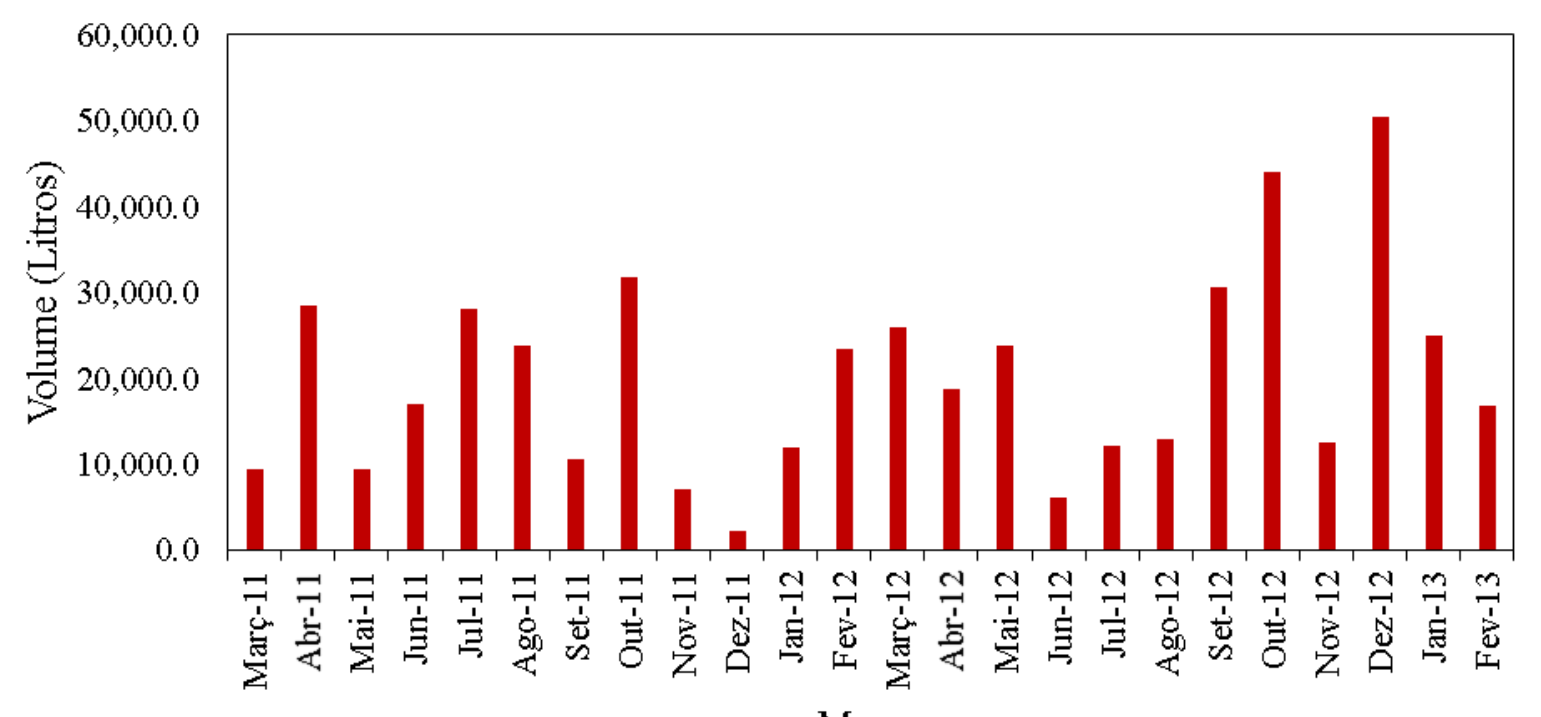

Figura 2 - Volume calculado da água de chuva no período e local do estudo

Os custos de instalação e equipamentos apresentam-se na (Tabela 1). Na análise econômica, os reservatórios representam o maior investimento $(63 \%)$ do custo total, seguido da lavadora $(27 \%)$, os 
outros $(10 \%)$ foram representados por materiais como: conexões, mangueiras, disjuntores e serviços. Para os cálculos do valor da água foram divididos em dois períodos, devido à diferença na tarifa. No ano de 2011, nos dez meses de análise, o custo da tarifa básica estava em $R \$ 16,23$ ao mês, gerando um custo de $R \$ 162,30$, com o acréscimo de $R \$ 1.345,43$ devido à taxa de $3,34 R \$ \mathrm{~m}^{-3}$ do volume armazenado, totalizou $\mathrm{R} \$ 724,34$. Já para janeiro de 2012 a fevereiro de 2013 o gasto foi de $\mathrm{R} \$ 238,98$, pois o custo da tarifa básica aumentou para $R \$ 17,07$ ao mês, somando-se mais $R \$ 1.046,34$ devido à taxa de 3,61 m³, totalizando $R \$ 1.285,32$. Obteve uma economia total de $R \$ 2.009,66$ ( $R \$ 83,74$ mês), caso fosse necessário pagar à concessionária (CORSAN). Através dos cálculos do custo da água, o tempo de recuperação de capital será de aproximadamente 144 meses, ou seja, em 12 anos. Esses últimos cálculos proporcionaram uma noção de quanto tempo à obra irá ser quitada, mas sabe-se que possivelmente, o custo da tarifa básica e a taxa para cada $\mathrm{m}^{3}$ cobrados pela concessionária sofrerão aumentos a cada novo ano, então a quitação das instalações desse Setor será em um período menor. A demora no retorno financeiro em relação ao pagamento dos equipamentos não é prejudicial ao Colégio, visto que é uma instituição educacional que promove a conscientização ambiental e difunde a ideia do desenvolvimento sustentável.

Tabela 1 - Custo de instalação e equipamentos para o setor da Mecanização do Colégio Politécnico da UFSM, Santa Maria, RS

\begin{tabular}{|c|c|c|c|}
\hline Descrição & $\begin{array}{c}\text { Quantidade } \\
\text { (Unidade) }\end{array}$ & $\begin{array}{c}\text { Valor unitário } \\
\text { (R\$) }\end{array}$ & $\begin{array}{c}\text { Preço total } \\
\text { (R\$) }\end{array}$ \\
\hline Caixa de água 7.000 litros & 5 & $1.530,00$ & $7.650,00$ \\
\hline Cano PVC $150 \mathrm{~mm}$ & 4 & 95,56 & 382,24 \\
\hline Te PVC $150 \mathrm{~mm}$ & 3 & 30,13 & 90,39 \\
\hline Curva PVC 150 mm & 3 & 49,49 & 148,47 \\
\hline Adaptador PVC 100-150 mm & 4 & 8,09 & 32,36 \\
\hline Cano PVC $32 \mathrm{~mm}$ & 3 & 13,28 & 34,84 \\
\hline Curva PVC $32 \mathrm{~mm}$ & 6 & 2,98 & 17,88 \\
\hline Te PVC $32 \mathrm{~mm}$ & 1 & 3,00 & 3,00 \\
\hline Registro PVC $32 \mathrm{~mm}$ & 1 & 17,83 & 17,83 \\
\hline Disjuntor trifásico $50 \mathrm{~A}$ & 1 & 50,04 & 50,04 \\
\hline Mangueira alta pressão $15 \mathrm{~m}$ & 1 & 31,62 & 31,62 \\
\hline Lavadora universal modelo luz 3501 & 1 & $3.300,00$ & $3.300,00$ \\
\hline Serviços & - & - & 300,00 \\
\hline Total (R\$) & & - & $12.058,67$ \\
\hline
\end{tabular}

\section{Discussão}

A produção acadêmica brasileira, segundo Gomes et al. (2014), no tocante à captação e armazenamento de água da chuva é reduzida, especialmente em áreas urbanas, tanto para fins potáveis ou não potáveis, contrastando com a crescente importância que esta temática tem adquirido nos últimos anos e, consequentemente, coloca em evidência o baixo impacto das pesquisas brasileiras sobre o tema na produção científica internacional, principalmente em relação aos desenhos físicos de sistemas, com o desenvolvimento de modelos para determinação de melhores parâmetros (dimensões dos reservatórios, das superfície de captação e das calhas, filtros, desvios automáticos da primeira água de chuva) por meio de estudos em escala piloto e simulação. Thomas (2001) comenta que a área de captação está diretamente relacionada ao potencial da água de chuva possível de ser aproveitada e, 
por sua vez, o material da qual é formada influenciará na qualidade da água captada e nas perdas por evaporação e absorção. Os telhados são mais utilizados para captação devido à melhor qualidade da água que este fornece. Os reservatórios representam o segmento mais oneroso do sistema de captação do aproveitamento da água de chuva, deve-se dimensioná-lo de forma bastante criteriosa. Seu custo pode representar entre $50 \%$ e $85 \%$ do valor total de um sistema de captação da água de chuva. Assim, sua escolha influenciará diretamente na viabilidade financeira da implantação do projeto.

Segundo, Lima et al. (2009) com o trabalho realizado na Instituição no Campus de Campo Mourão da Universidade Tecnológica Federal do Paraná-PR, com o aproveitamento da água de chuva utilizado para a lavagem de pisos, descargas sanitárias e rega de jardins proporcionaram a redução do consumo de água potável do poço artesiano e consequentemente auxiliaram na preservação da água do manancial subterrâneo.

Também, Queiroz e Farias (2012) realizaram estudos para avaliar o potencial do aproveitamento da água de chuva para fins não potáveis no Campus da Universidade Federal de Campina Grande em Pombal-PB, concluíram que a demanda ao longo do ano só será atendida plenamente se o volume dos reservatórios for cinco vezes maior que a demanda porque é grande a variabilidade pluviométrica do local. Para Scherer (2003), os edifícios escolares são uma fonte potencial para a implantação de sistemas prediais de aproveitamento das águas pluviais para fins não potáveis, pois geralmente apresentam grandes áreas de telhados e outras coberturas. Para a implantação desses sistemas, são necessários estudos de viabilidade técnica e econômica, verificando o potencial de economia de água potável e determinando a relação entre custo e benefício.

Além disso, Ornelas (2004) comenta que quando for possível substituir a água potável por água de reuso, ajudará a manter a sustentabilidade desse valioso recurso e, o recolhimento da água de chuva possibilita a utilização para diversos fins, diminuindo o uso da água do subsolo e contribuindo na preservação do meio ambiente. Também, Gould, Nissen e Petersen (1999, apud CAMPOS et al., 2004), onde a água de chuva pode ser utilizada como alternativa para alguns casos como: descarga de vasos sanitários; irrigação de jardins e lavagens de carros, pisos e passeios, em que a implantação do sistema se torna útil para residências que possuem consumo de água elevado, em torno de $25 \mathrm{~m}^{3}$, substituindo o uso de água potável em atividades grosseiras, fenômeno este que surgiu a partir no século XXI.

O aproveitamento da água de chuva assegura a redução dos custos financeiros com os serviços de abastecimento de água nos vários setores a que ela é destinada, consequentemente, ocorrerá à preservação da água no meio ambiente e a conservação de um dos bens naturais mais escassos (GUIMARÃES et al., 2015).

\section{Conclusão}

O sistema de aproveitado da água de chuva é uma das alternativas para a diminuição do consumo de água de outras fontes. Com o projeto foi deixado de utilizar a água do sobsolo. Esta alternativa é modelo de conservação existente entre o ser humano e a natureza para atingir a sustentabilidade.

\section{Agradecimentos}

A todos que de alguma maneira colaboraram para a elaboração e execução deste projeto. Ao Colégio Politécnico da Universidade Federal de Santa Maria pelo aporte.

\section{Referências}

ALT, R. Aproveitamento de água de chuva para áreas urbanas e fins não potáveis-Estudo baseado no curso ABNT de 11-02-2009 SP/SP do Engo․ Plínio Tomaz. São Paulo. 2009. 
CAMPOS, M. A. S. Aproveitamento de água pluvial em edifícios residências multifamiliares na cidade de São Carlos. 2004. Dissertação (Mestrado em Engenharia Civil) - Universidade Federal de São Carlos, 2004.

COHIM. E.; GARCIA, A. P.; SILVA, A.; KIPERSTOK, A. Dimensionamento de reservatório para captação de água de Chuva para irrigação. In: Anais, 6오ํ Simpósio Brasileiro de Captação de Água de Chuva, Belo Horizonte, MG, 2007.

FANTINEL, A. L.; NOGUEIRA, C. U.; NOGUEIRA, H. M. C. de M.; MUNDT, R. D.; CECONI, C. A.; SANTIAGO, F. (2013). Reaproveitamento da água da chuva para a irrigação do ambiente climatizado da floricultura do Colégio Politécnico da UFSM. 2oㅜ Fórum Internacional Ecoinovar, Santa Maria/RS - 23 e 24 de setembro de 2013.

GIACCHINI, M. Estudo quali-quantitativo do aproveitamento da água da chuva no contexto da sustentabilidade dos recursos hídricos. 2010. 132 f. (Dissertação Mestrado) - Programa de PósGraduação em Engenharia de Recursos Hídricos e Ambiental, Universidade Federal do Paraná, Curitiba, 2010.

GIACCHINI, M.; A. FILHO, A. G. de. Utilização da água de chuva nas edificações industriais. In: Anais. II Encontro de Engenharia e Tecnologia dos Campos Gerais, 2008.

GIL, A. C. Métodos e técnicas de pesquisa social. 4. ed., São Paulo: Atlas, 1994.

GOMES, U. A. F.; DOMÈNECH, L.; PENA, J.; HELLER, L.; PALMIER, L. Captação de Água da Chuva no Brasil: Novos Aportes a Partir de um Olhar Internacional. Revista Brasileira de Recursos Hídricos. v.19, n.1, 7-16, 2014.

GOULD, J.; NISSEN-PETERSEN, E. Rainwwater catchment systems for domestic supply: Design, construction and implementation. Londres, ITDG Publishing, p. 335, 1999.

GUIMARÃES, B. V. C.; SOUZA, E. B. de; ABREU, A. M. A.; DONATO, S. L. R.; ASPIAZU, I. Captação e aproveitamento da água da chuva para fins não potáveis e potáveis. Enciclopédia Biosfera, Centro Científico Conhecer - Goiânia, v.11 n.21; p. 2926, 2015.

HESPANHOL, I. Potencial de reuso de água no Brasil: agricultura, indústria, municípios, recarga de aquíferos. Revista Brasileira de Recursos Hídricos, v.7, n.4, 75-95, 2002.

INMET. Instituto Nacional de Meteorologia do Brasil. Ministério da Agricultura, Pecuária e Abastecimento, 2013. Disponível em: http://www.inmet.gov.br/portal/index.php?r=home2/index

JAQUES, R. C. Qualidade da água de chuva no município de Florianópolis e sua potencialidade para aproveitamento em edificações. Dissertação (Mestrado em Engenharia Ambiental) - Universidade Federal de Santa Catarina. Florianópolis, SC, Brasil, p. 102, 2005.

LIMA, A. N. D.; FERREIRA, R. C.; PORFÍRIO, M. A. S.; SOUZA, D. C. D.; PASSIG, F. H.; CARVALHO, K. Q. D. Aproveitamento de água de chuva para usos não potáveis no campus Campo Mourão da Universidade Tecnológica Federal do Paraná. Olam-Ciência\& Tecnologia, Rio Claro, v.1, n.2, 124-161. 2009.

MAY, S. Estudo da viabilidade do aproveitamento de água de chuva para consumo não potável em edificações. Dissertação (Mestrado em Engenharia de Construção Civil e Urbana) - Escola Politécnica da Universidade de São Paulo, São Paulo, 2004. 
MOTA, M. B. R; MANZANARES, M. D.; SILVA, R. A. L. Viabilidade de reutilização de água para vasos sanitários. Revista Ciências do Ambiente [On-Line]. v.2, n.2, 2006.

ORNELAS, P. Reuso de água em edifícios públicos: o caso da Escola Politécnica da UFBA. Dissertação (Mestrado em Gerenciamento e Tecnologias Ambientais no Processo Produtivo) - Departamento de Engenharia Ambiental, Universidade Federal da Bahia, 2004.

P. N. U. D. Programa das Nações Unidas para o desenvolvimento. Ranking do IDH dos Estados em 2006, p. 52. 2006.

QUEIROZ, M. M. F de; FARIAS, C, A, S, de. Potencial de aproveitamento de águas pluviais para fins não potáveis no Campus da UFCG em Pombal-PB. In: Anais. $8^{\circ}$ Simpósio de Brasileiro de captação e Manejo de Água da Chuva. Campina Grande, 2012.

SANTOS, C. A. G.; SANTOS, K. M. dos; MEDEIROS, M. P.; NÓBREGA, R. D. da; COSTA, I. Y. de L. G. da. Aproveitamento de água de chuva para fins não potáveis. In: Anais. X Encontro de Extensão; XI Encontro de Iniciação à Docência, João Pessoa. UFPB, v.1. p. 1-9, 2008.

SCHERER, F. A. Uso Racional da Água em Escolas Públicas: Diretrizes Para Secretarias de Educação. Dissertação (Mestrado) - Curso de Pós-Graduação em Engenharia da construção Civil, Escola Politécnica, Universidade de São Paulo, São Paulo, 2003.

THOMAS, T. Escolha de cisternas para captação de água de chuva no sertão. In: Anais do 3ํㅗㅅ Simpósio Brasileiro de Captação de água de Chuva no Semi-árido. Campina Grande. Petrolina: ABCMAC. CD-ROM. 2001.

TOMAZ, P. Água pague menos (Org.). In: Aproveitamento de água de chuva, 2010.

TOMAZ, P. Aproveitamento de água de chuva para áreas urbanas e fins não potáveis. $4^{\mathrm{a}}$ ed. São Paulo: Navegar Editora. 2011. 